\title{
GOVERNANÇA PARAA SUSTENTABILIDADE URBANA E A REGULARIZAÇÃO FUNDIÁRIA
}

\section{GOVERNANCE FOR URBAN SUSTAINABILITY AND LAND REGULARIZATION}

\author{
Maykon Fagundes Machado ${ }^{1}$ \\ Zenildo Bodnar ${ }^{2}$
}

Kaira Cristina Silva ${ }^{3}$

Resumo: A presente pesquisa tem como escopo verificar a governança urbana sob um viés sustentável de forma a abranger a cidade e proporcione a garantia de direitos individuais e coletivos, de forma específica, busca-se ainda enfatizar a importância da regularização fundiária no contexto da cidade, um instrumento garantidor do efetivo direito a moradia, convertendo o título de posse em propriedade, principalmente concernente à população que vive em condições de extrema precariedade e necessita do devido acesso as políticas públicas e por fim concluir que a compreensão da sustentabilidade é fundamental na atualidade, principalmente concernente a percepção da teia da vida, o entendimento de que tanto o ser humano, como o meio ambiente e a comunidade não viva estão interligados em uma relação sistêmica. Para a percepção geral da justificativa e para a construção deste artigo científico foi utilizada a base lógica do método indutivo de

1 Acadêmico de Direito atualmente no $5^{\circ}$ período pela Universidade do Vale do Itajaí (Univali). Pesquisador-Bolsista (PIBIC-CNPq), desenvolvendo pesquisas na área do Direito, com ênfase em sustentabilidade, direito urbano e políticas públicas. E-mail: maykonfm2010@hotmail.com.

2 Possui graduação em Direito pela Universidade Estadual de Ponta Grossa, Mestrado em Ciência Jurídica pela Universidade do Vale do Itajaí; Mestrado em Urbanismo, História e Arquitetura da Cidade (PGAU-Cidade) pela UFSC na linha de pesquisa Meio Ambiente e Planejamento Urbano; Doutorado em Direito pela Universidade Federal de Santa Catarina (2005), Pós-Doutorado em Direito Ambiental na Universidade Federal de Santa Catarina e Pós-Doutorado em Direito Ambiental na Universidade de Alicante (Espanha). Professor dos Programas de Doutorado e Mestrado na Universidade do Vale do Itajaí (Univali). E-mail: zenildo@univali.br

3 Mestranda em Ciência Jurídica pelo Programa de Pós-Graduação Stricto Sensu em Ciência Jurídica da Universidade do Vale do Itajaí. Bolsista do Programa de Suporte à Pós-Graduação de Instituições de Ensino Particulares - PROSUP/CAPES. Pós-Graduada em Direito Penal e Processual Penal pela Escola do Ministério Público de Santa Catarina (MPSC). Graduada em Direito pela Univali. E-mail: kairasilva@outlook.com 
procedimento bibliográfico.

Palavras-chave: Governança urbana. Regularização fundiária. Sustentabilidade.

Abstract: The research aims to analyze urban governance according to a sustainable bias that is able to thoroughly cover a city and provide the entitlement of both personal and collective rights. Too, in a specific way, it seeks to emphasize the importance of land regularization in the context of a city, an instrument that entitles people to housing, turning possession of land into a deed of free hold state, especially for the people that live in conditions of extreme poverty and are in need of due access to public policies; therefore, it is important to conclude that the understanding of sustainability is fundamental nowadays, mainly in the scope of the perception of life, the understanding that the human being, the environment, and the non-living community have been linked underneath a systemic relationship. For the general perception of the justification and for the construction of this scientific article it was used the logical base of the inductive method of bibliographic analyses.

Keywords: Urban governance. Land regularization. Sustainability.

\section{INTRODUÇÃO}

Vivemos em uma geração que carece de uma conscientização ambiental, isto é, desde a criança ao adolescente, chegando ao adulto, necessita-se de uma adequada alfabetização ecológica para que se obtenha uma sociedade sustentável. Sendo assim, para gerir uma sociedade, torna-se imprescindível o papel de uma governança sustentável, que se trata basicamente da interação conjunta de atores políticos, sociais e econômicos em prol da sociedade adotando um caráter sustentável em suas deliberações, mas neste contexto também é imprescindível a participação da sociedade civil.

De acordo com Bosselmann (2015, p. 87): “[...] sem a participação efetiva da sociedade civil e a transparência da governança, o desenvolvimento sustentável continuará a ser uma promessa não cumprida."

Entretanto, apesar de uma visão macro ser necessária e real, no que tange aos aspectos globais da sustentabilidade, teremos que analisar igualmente as cidades. Efetivar o princípio 
da sustentabilidade no cenário local frente ao exacerbado desenvolvimento econômico torna-se um grande desafio.

Ao adentrar no conceito de cidade sustentável que abrange uma série de direitos fundamentais, destacamos a questão do direito a moradia e, para isso, identificamos que há uma grande desigualdade entre os centros urbanos e a chamada periferia, pois não usufruem dos direitos e garantias fundamentais de forma igualitária, um instrumento para retirá-los da margem da lei e estabelecer seu devido direito à moradia, chama-se regularização fundiária.

O objeto da presente pesquisa é a análise da categoria governança sustentável e a sustentabilidade frente aos seus desafios de estabelecer a efetividade de direitos fundamentais, como o direito à moradia, por meio de políticas públicas essenciais.

O objetivo geral surge para analisar a governança para a sustentabilidade urbana nos contextos de informalidade e vulnerabilidade social e ambiental e investigar a regularização fundiária como instrumento de mutabilidade das cidades informais e marginalizadas para a promoção de um novo paradigma urbano socioambiental, cidade sustentável.

Os objetivos específicos buscam apresentar uma caracterização geral da governança para a sustentabilidade urbana que incluiu estruturas e autoridades envolvidas na proteção do meio ambiente e dos direitos fundamentais da cidade sustentável; Analisar a implementação da formalização do acesso a terra e a moradia como preceito fundamental para a sustentabilidade urbana, por intermédio da regularização fundiária plena; Identificar os atores sociais e a tutela de direitos fundamentais no paradigma de governabilidade urbana, destacando a importância da participação cidadã; averiguar os aspectos legais basilares da regularização fundiária e o reconhecimento dos direitos inerentes, conforme previstos nos dispositivos constitucionais 
e infraconstitucionais; enfatizar a importância da regularização fundiária no contexto da cidade, um instrumento garantidor do efetivo direito a moradia, convertendo o título de posse em propriedade, principalmente concernente à população que vive em condições de extrema precariedade e necessita do devido acesso as políticas públicas e a justiça e, por fim, ressaltar que a compreensão da sustentabilidade é fundamental, tanto no cenário global como local.

A metodologia (métodos e técnicas) escolhida para a elaboração deste artigo considerou as fases da Pesquisa Científica (PASOLD, 2015, p. 85-111).

sob tal referente, na fase de investigação foi empregado o método dedutivo; na fase de tratamento de dados, o método analítico; e, na fase de relato, portanto na elaboração deste artigo científico, foi utilizado o método indutivo. A técnica que forneceu o suporte aos métodos foi a de pesquisa bibliográfica.

\section{GOVERNANÇA URBANA SUSTENTÁVEL}

A Constituição de 1988 ao abordar o tema urbanidade, enfatiza a importância da tutela entre os direitos atinentes à sociedade em consonância com a preservação ambiental, dispondo muito além de meras condições de subsistência, é preciso resguardar princípios e direitos fundamentais do cidadão inserido na sociedade, e para isso, surge a ideia de uma governança sustentável, indo ao encontro à coletividade como num todo - meio ambiente/cidadão.

Em relação à temática governança urbana, Rhodes caracteriza governança como uma mudança no entendimento de governo, significando um novo processo de governação ou uma mudança das regras ou ainda um novo método pela qual a sociedade é governada. Esse novo método vem de forma inovadora trazer a ideia de uma cooperação com os agentes políticos 
bem como com os cidadãos de uma forma que proporcione a igualdade, tanto ricos como pobres sendo amparados sem distinção. O princípio da participação se torna fundamental nesta tese a ser implementada (RHODES, 1996, p. 652-653).

$\mathrm{Na}$ visão de Cymbalista, aqueles que estão do "lado de dentro" conseguem ser muito bem amparados pelas políticas públicas decorrentes de uma boa gestão, possuem acesso às bibliotecas, universidades, museus. Geralmente tais áreas surgem em porções mais consolidadas das cidades, em contraponto a periferia padece pela ganância do mercado que provoca tal separação, estimulando a indiferença por meio de aparatos de vigilância e segurança, não promovendo assim uma governança solidária entre a sociedade, o governo e o meio ambiente (CYMBALISTA, 2008, p. 281-282).

Uma das razões para o surgimento do conceito governança, ou governança urbana, na visão de Stephens e Wikstromé, que o contexto que o governo local opera está se tornando cada vez mais amplo e complexo. Nos Estados Unidos, os investigadores tratam problemas metropolitanos cada vez mais usando o termo "governança metropolitana", em vez de "governo metropolitano" por causa das conotações mais inclusivas do antigo (STEPHENS, G. R., \& N. WIKSTROM, 2000, p. 47).

Um dos grandes desafios da governança pode se conceituar como sendo um desafio quadripartite, isto é: organizador, facilitador, fiscalizador e regulador, no qual, deve fomentar e interagir com os demais agentes sociais para que de forma democrática e participativa se construam planos de gestão e acordos setoriais de relevância notável em prol da coletividade e do meio ambiente (ZANTA, 2014, p. 78).

Percebe-se que o conceito governança urbana de certa forma possui uma ampla "[...] relação com as novas práticas de coordenação de atividades por intermédio de redes, 
parcerias e fóruns deliberativos que cresceram nas ruínas da representação corporativista mais centralizada e hierárquica do período até os anos 70" (HIRST, 2000, p. 18, tradução nossa). Importante destacar a importância das redes sociais como parceiras de governos na governança urbana, como preconiza Frey, cabe destaque à ascensão das redes sociais que estão vindo em combate as redes tradicionais seletivas dos grupos sociais dominantes. A iniciativa de governos locais em criação de conselhos municipais deliberativos, orçamentos participativos e a própria Agenda 21 representam tentativas de romper com este consenso da elite, criar contra poderes capazes de promover a igualdade e a democracia, bem como garantir à população em geral o acesso aos recursos financeiros e informacionais, aos serviços públicos e às arenas de tomada de decisão política (FREY, 2003).

Ao se deparar com esta relevante temática, que aborda a governança em um aspecto sustentável, tem de pensar que estamos tratando de um tema novo, entretanto a política e a governança sustentável não são assuntos assim tão novos no que tange o município e sua gestão. Atividades tradicionalmente a cargo dos municípios são na verdade indissociadas de sua atribuição ambiental. Essas atribuições já lhes pertencem há muito e são exercidas com distintos graus de qualidade. Está em curso o processo de transformação da cultura da cidade, bem como das políticas públicas que outrora visavam tão somente o indivíduo. Nessa nova perspectiva sustentável, rompemos paradigmas para promover uma boa governança, inserindo regulações que integram paradigmas de defesa ambiental, como ocorrido no setor de saneamento, resíduos sólidos e ordenamento urbano (NEVES, 2014).

$\mathrm{Na}$ contemporaneidade quando se fala em governança associada às discussões de reforma de estado, na verdade ela está abrigando considerações sobre a eficácia e a efetividade 
na gestão dos governos. Ao se tratar de governança sustentável estamos dispondo da mesma linha de pensamento, temos que analisar o que estes governos que emergem e surgem com poder tem feito pelo meio ambiente. Por essa afirmação, os pesquisadores e autoridades do tema costumam adjetivá-la como pública ou local, visando diferenciar distintas aplicações na prática. Por exemplo, o conceito de "governança pública" surgiu no âmbito da Administração Pública e da Ciência Política, e sua definição denota um novo padrão de gestão pública e de desenvolvimento, que passa a articular os diversos atores políticos, administrativos e sociais. Logo, quando nos referimos a gestão urbana local, no que tange às cidades e regiões metropolitanas, associa-se comumente ao termo "governança local", a qual necessita fortemente de engajamento dos atores sociais e políticos que possuam preparo para lidar com a governança sustentável dentro da cidade. Esse, com certeza, é um grande desafio (ARAÚJO, 2016, p. 9).

Nesse contexto, percebemos que governança se distingue de governo, refere-se à relação entre civis, a sociedade e o Estado, entre governantes de governo e governados que irão debater acerca de ideias sustentáveis e futuras. Sob esse prisma é que a participação do cidadão deve ser atuante de fato. Em suma, “[...] é este último aspecto-a relação da sociedade civil com o estado-que distingue o estudo da governança de outros estudos de governo". (McCARNEY, P., M. HALFANI \& A. RODRIGUEZ, 1995, tradução nossa).

Klaus Bosselmann enfatiza a necessidade de conciliar o desenvolvimento econômico com a proteção do meio ambiente, é preciso pensar a governança sustentável sob este enfoque (BOSSELMANN, 2015). Uma boa gestão da cidade antigamente, nos conceitos tradicionais, era aquela que proporcionava empregos e gerava renda, isto é excelente, contudo o desenvolvimento sustentável surge a partir da CRFB/88, 
disposto no art. 225 com a seguinte preocupação de que é preciso pensar no próximo - pensar no meio ambiente, crescer a economia juntamente com a sustentabilidade, tanto nesta como nas futuras gerações.

Igualmente, nota-se que o conceito de governança ambiental é fundamentalmente diferente do conceito de governança para a sustentabilidade, é considerada o "primo pobre" da governança econômica, isso porque irá abordar apenas superficialmente de forma minimalista os fatores sociais em relação ao meio ambiente, é preciso ir além. A governança para a sustentabilidade traz consigo a preocupação do meio ambiente como um todo é necessário pensar no ser humano igualmente como se pensa os rios, mares, florestas, cidades entre outros. O tradicional foco da governança atual é a comunidade humana, o novo foco deve ser a comunidade mais ampla da vida, a inclusão de toda a vida (além da vida humana) é um grande avanço.

Observamos um legislativo que formula leis de interesse público diuturnamente, porém com o novo conceito de governança, o público se expandiria. Utilizando o princípio da sustentabilidade como norte para projetos de lei, e governança urbana a níveis locais e regionais, teremos grande progresso, beneficiando toda a comunidade terrestre e aceitando que não somente o ser humano se beneficia com tais atitudes, mas toda a comunidade viva (BOSSELMANN, 2015, p. 220-221).

A Carta da Terra igualmente nos conscientiza sobre a importância do meio ambiente e tem por ambição levar adiante a sociedade da sustentabilidade global fundada no respeito à natureza, direitos humanos, universal, justiça econômica e cultura de paz. A Carta reúne uma série de princípios, entretanto cabe destaque a preocupação ambiental. $\mathrm{O}$ meio ambiente não é visto como meramente um recurso base para o consumo humano, mas como um pilar - base para toda a vida. Para promo- 
ver uma governança sustentável local, ou ainda sim global - o grande objetivo, a Carta ressalta a importância da cooperação e do exercício da cidadania desde o começo, no seu preâmbulo que proclama: Nós somos cidadãos de diferentes nações e de um mundo em que o local e o global estão ligados. Todos dividem a responsabilidade para com o presente e futuro bemestar da família humana e de toda a vida terrestre. A parceria do governo, sociedade civil, e negócios se torna essencial para uma governança efetiva, e para construir um mundo melhor, as nossas obrigações devem ser cumpridas, desde pequenos atos com o meio ambiente, quanto às obrigações a serem cumpridas na esfera internacional (BOSSELMANN, 2015, p. 222-224).

\section{REGULARIZAÇÃO FUNDIÁRIA, SUA APLICABILIDADE E DESAFIOS}

O conceito de regularização fundiária está previsto no art. 46 da Lei n. 11.977/2009, que estabelece que é imprescindível atentar para os aspectos urbanísticos, que exigem o desenho das vias de circulação, a observância do tamanho dos lotes, a alocação de casas precárias ou situadas em situação de risco, tudo para que esse espaço urbano venha a realmente se integrar na cidade. Além disto, é fundamental que se realize a regularização jurídica das áreas a fim de que se dê segurança aos moradores. E todo o processo deve levar em conta os aspectos ambientais e sociais, envolvendo toda a população.

O que ocorre é que a informalidade das submoradias compromete a dignidade das pessoas. Elas não têm como fruir do seu direito à cidade e, portanto, nem são efetivamente cidadãs. Morar irregularmente é o mesmo que navegar em permanente insegurança. Além disso, a regularização fundiária repercutirá na gestão racional dos territórios urbanos, já que, regularizados, os assentamentos passam a integra os cadastros municipais (NALINI, 2014, p. 6). 
Verifica-se com clareza a existência de duas finalidades imediatas a regularização fundiária. A primeira delas é a adoção de medidas para a regularização do próprio assentamento. Trata-se de um conjunto de ações que visam implementar os equipamentos públicos previstos da Lei n. 6.766/1979 como forma de conferir elementos essenciais à dignidade da pessoa humana. [...] sob um segundo aspecto, visa, com a regularização do empreendimento, a titulação de seus ocupantes (NALINI, 2014).

Nalini (2011, p. 38) sob esse prisma destaca que:

[...] a moradia é essencial à dignidade da pessoa humana, nesta lógica nota-se que a moradia é o direito social fundamental do cidadão. Direito fundamental social prestacional, para ser mais exato. Aquele que reclama uma prestação concreta do Estado, para que seus titulares possam exercê-lo. Compreende-se seja assim. O teto é imprescindível à garantia da maior parte de todos os demais direitos pertinentes ao ser pensante.

Em suma, a regularização fundiária é um legítimo instrumento que possibilita a dignidade dos moradores que foram compelidos a ocupar ou comprar terrenos nessa situação. Isto ocorre com frequência em relação aos moradores de baixo nível aquisitivo, que por consequência de sua precária condição, se submetem a viver em moradias irregulares e em lastimável estado. Isso se deve principalmente pela omissão do estado na gestão e criação de políticas públicas, a regularização fundiária não é interesse exclusivo do ocupante irregular. A incompatibilidade jurídica da posse impossibilita investimentos em políticas públicas, incluindo saneamento, infraestrutura urbana e melhoria da qualidade de vida. Além disso, é direito fundamental a todos oponível. Primeiramente ao Estado, que se omitiu e deixou que a situação chegasse ao descalabro (NALINI, 2011).

É importante destacar que o direito fundamental da mo- 
radia é reconhecido em inúmeros tratados e instrumentos internacionais (BOSSELMANN, 2015). Contudo, ainda sim, se percebe a incapacidade de concretizá-lo com eficácia. Um exemplo de previsão legal que deve(ria) ser seguido à risca é o estatuto da cidade. O estatuto da cidade "[...] introduz o conceito legal de garantia do direito a cidades sustentáveis. Direito fundamental a ser titularizado por todas as pessoas. $\mathrm{O}$ direito a ordem urbanística também está explicitado". (NALINI, 2011, p.139). Sob este viés, cabe dizer que o direito deve ser igualitário e sine qua non, isto é para todos de forma isonômica e justa, não se deve favorecer somente os grandes empresários e a grande massa econômica, o que se busca é uma efetivação da igualdade de direitos.

Ainda, de suma importância é observar a função social da propriedade nesse contexto. Além de configurar princípio jurídico, a função social da propriedade também possui natureza de regra jurídica, desde que materializada pelo diploma responsável por estabelecer as diretrizes urbanísticas da cidade. $\mathrm{O}$ plano diretor, igualmente um importante instrumento que tem tal desiderato, deve indicar o conteúdo da função social, atendendo às peculiaridades de cada cidade. Atuando nesse sentido, estará concretizando a chamada função social da propriedade (NALINI, 2014).

Salles (2014, p. 86) na mesma produção dirigida por Nalini em relação à função social da propriedade destaca que:

$\mathrm{Na}$ condição de princípio constitucional, e vetor de toda legislação infraconstitucional (Estatuto da Cidade, Lei n.10.257/2001, e o Plano Diretor), a função social deve ser entendida com o implemento dos vários instrumentos legais. Dentre estes, assume especial relevância, pela desorganização e de informalidade dominial nos grandes centros urbanos, a regularização fundiária urbanística, que tem a meta da urbanização, com o aparelhamento da região ou área dos serviços públicos que compõem a infraestrutura básica e ne- 
cessária e titulação dominial, mediante o reconhecimento ou declaração do direito de propriedade aos moradores.

Em relação aos atores envolvidos na regularização fundiária, teremos a presença do Município, Ministério Público, Defensoria Pública ou Serviço de Assistência Jurídica dos Municípios, Registro de Imóveis, Poder Judiciário e os ocupantes das respectivas áreas. Quanto ao Município, cabe a ele ordenar o uso do solo, sendo de fato o principal ator na regularização fundiária, aprovando os projetos de interesse coletivo no que concerne, inclusive, ao tema abordado, mesmo que elaborado por outras instituições. Nesse contexto, a parceria e a união com os outros órgãos e instituições envolvidas são fundamentais e indispensáveis.

O Ministério Público sendo instituição permanente que atua na defesa da ordem jurídica exercendo, inclusive, o papel de custos legis, buscando o devido regime democrático e a consolidação dos direitos sociais e individuais indisponíveis, irá atuar na defesa do direito social a propriedade, bem como em prol do direito difuso atinente à ordem urbanística, podendo ingressar com inquérito civil e com ação civil pública para que a regularização fundiária seja concretizada.

A Defensoria Pública e/ou a Assistência Jurídica dos Municípios possuem a responsabilidade de atender os ocupantes das áreas irregulares, proporcionando aos menos favorecidos um atendimento de qualidade que repercutirá na concretização do direito social dos cidadãos. Quanto à incumbência do Registrador de Imóveis, destaca-se que a propriedade imóvel é constituída de maneira formal, por meio da apresentação do título hábil ao Registro de Imóveis. Se não há um título, não há condições jurídicas de constituir a propriedade. Quando há a falta do título, somente há a posse sobre o imóvel (propriedade informal). Nesse contexto, a presença do registrador imobiliário é de extrema importância, pois viabilizará a 
celeridade quanto à regularização fundiária, evitando a inaptidão dos títulos apresentados.

Sob esse prisma, a função do registrador imobiliário se dará em dois aspectos: garantidor da segurança jurídica e profissional do direito que irá auxiliar o cidadão mostrando-lhe o caminho que deve ser seguido para efetivar seu direito, bem como trazer todo o auxílio jurídico possível quanto a área, suas extensões, confrontações e demais informações, nos conformes da lei. Ainda, cabe dizer que é a atividade cartorial que confere a conversão da titulação da posse em propriedade, aos contemplados pela regularização fundiária de interesse social.

No que concerne à atuação do Poder Judiciário, este estará responsável por eventuais ações de usucapião em determinados casos, bem como para a suscitação de dúvida em procedimentos em que o registro de imóveis é o atuante. Destaca-se ainda a importância da participação dos ocupantes da área e a câmara municipal. Sem a participação efetiva da parcela da sociedade que carece desses direitos, bem como toda a sociedade, é impossível agir. É necessária a conscientização da sociedade sobre esses direitos que por vezes são esquecidos. O contato prévio das instituições com a população é de suma importância.

E ainda, a câmara trará às aprovações de leis e projetos pertinentes a concretização destes direitos (ZEIS, Plano Diretor, leis de concessão etc), bem como outras políticas públicas pertinentes para o exercício dos direitos fundamentais, como, por exemplo, no Estado de Santa Catarina temos o "Programa Lar Legal" - responsável para a concessão de títulos de propriedade e garantidor da regularização fundiária, projetos assim são de grande relevância para a população.

Existem várias modalidades de regularização fundiária previstas no ordenamento jurídico, tais como a regularização fundiária de interesse social, regularização fundiária de interesse específico, regularização fundiária inominada, regu- 
larização fundiária de interesse social em imóveis públicos, autorizada pela Lei n. 11.481/2007. Todas as modalidades possuem peculiaridades e são de extrema importância para a consolidação dos direitos e garantias individuais, principalmente ao direito à moradia. Apesar de não detalhar em suas minúcias, destaca-se que é imprescindível conhecê-las e quando necessário, utilizá-las.

Em suma, Prestes citando Nalini (2011, p. 167, grifo nosso) demonstra que é imprescindível enfrentar a regularização fundiária nas suas três dimensões:

[...] urbanísticas, com a realização dos investimentos necessários para a melhoria das condições de vida; jurídica, com o reconhecimento da posse, utilizando os instrumentos que possibilitam a aquisição da propriedade nas áreas privadas e com a concessão do direito à moradia nas áreas públicas; e registraria, anotando nas perspectivas matrículas a aquisição destes direitos, a fim de atribuir eficácia erga omnes para todos os efeitos da vida civil.

$\mathrm{O}$ reconhecimento dos direitos fundamentais ultrapassa o centro urbano, toda a sociedade deve ser beneficiada pelas políticas públicas, e para isso, que surgem tais instrumentos fundamentais para a consolidação da democracia. Visar o ser humano como portador de direitos abrange uma série de fatores que devem ser considerados em suas peculiaridades, o direito a moradia digna e legítima é um grande passo para a efetivação da dignidade humana.

\section{SUSTENTABILIDADE URBANA E O DESENVOLVIMENTO SUSTENTÁVEL}

Definir um conceito para sustentabilidade não é plenamente viável, pois o que se busca não é estabelecer um conceito exclusivo de um determinado autor e segui-lo, vez que a sustentabilidade se desenvolve a cada dia na sociedade de risco que vivemos e possui diversos desdobramentos. 
Contudo, para pensar a sustentabilidade deve-se olhar para além das fronteiras, pois os danos ambientais afetam não somente os cenários locais, mas ultrapassam até mesmo os limites soberanos dos países. Isso deve ser motivo de preocupação, pois de nada adiantaria se determinado país adotasse medidas extremamente sustentáveis, sendo que outros rompem com tratados e pactos internacionais para degradar e poluir o planeta terra.

De acordo com o que preconiza BOFF (2013, p. 17):

A sustentabilidade deve ser pensada numa perspectiva global, envolvendo todo o planeta, com equidade, fazendo o que o bem de uma parte não faça à custa do prejuízo da outra. Os custos e os benefícios devem ser proporcional e solidariamente repartidos. Não é possível garantir a sustentabilidade de uma porção do planeta deixando de elevar, na medida do possível, as outras partes ao mesmo nível ou próximo a ele.

Tal reflexão é válida, pois o meio ambiente, o ser humano e até mesmo o ser não humano não estão separados em categorias em relação ao mundo. Todos estamos interligados em laços inseparáveis de vida. Essa interligação é o que denomina de Teia da Vida (TRINDADE et al., 2015, p. 203-204), e pode ser entendida igualmente pela teoria de Santiago (CAPRA, 2005, p. 50). Capra (2006, p. 135) ainda sob esse prisma destaca que:

Compreender a natureza da vida a partir de um ponto de vista sistêmico significa identificar um conjunto de critérios gerais por cujo intermédio podemos fazer uma clara distinção entre sistemas vivos e não vivos. Ao longo de toda história da biologia, muitos critérios foram sugeridos, mas todos eles acabavam se revelando falhos de uma maneira ou de outra. No entanto, as recentes formulações de modelos de auto-organização e a matemática da complexidade indicam que hoje é possível identificar esses critérios. A ideia-chave da minha síntese consiste em expressar esses critérios em termos das três dimensões conceituais: padrão, estrutura e processo.

Entender que estamos unidos neste ecossistema é compreender que quando falamos em proteção ambiental e desen- 
volvimento sustentável, não olhar com uma visão antropocêntrica em benefício do homem, toda a comunidade viva deve ser beneficiada como um todo, não em detrimento de alguns em favor de outros.

Sendo assim, tratar a terra como um baú de recursos é grande erro. Durante os séculos a terra vem sendo tratada meramente como uma res extensa (uma coisa meramente extensa), com valores pautados unicamente em benefício do homem. Devastamos cerca de $83 \%$ do planeta, e os $17 \%$ restantes, felizmente são áreas inacessíveis ao homem. Em suma, romper com essa visão antropocêntrica extraída até mesmo da Bíblia é grande avanço. O homem não foi feito para dominar e destruir todo o meio ambiente ao seu redor, mas para existir juntamente com ele, e ainda que necessite de recursos naturais, que extraia de forma sustentável e consciente (BOFF, 2015).

Bobbio (2004, p. 06) afirma que o direito fundamental ao Meio Ambiente constitui-se de direitos de terceira dimensão: "[...] O mais importante deles é o reivindicado pelos movimentos ecológicos: o direito de viver num ambiente não poluído". Porém há críticos dessa posição, como por exemplo, Eduardo Gudynas, que entende a questão dentro de concepção de cidadania que dele denomina de Meta-Cidadanias Ecológicas (GUDYNAS, 2009). Esses direitos transindividuais que surgem na modernidade não podem excluir a comunidade não humana, aderindo ao conceito antropocêntrico de sustentabilidade, e para que isso não ocorra, é preciso uma conscientização civil e uma efetivação nas decisões de cortes internacionais, dispondo sobre o princípio da sustentabilidade.

Em relação à temática Meio Ambiente, foi reconhecida a importância do dever de solidariedade, sob a relatoria do Ministro Celso de Mello (BRASIL, 1995), que pontuou no Supremo Tribunal Federal, o Meio Ambiente é direito de todos, isto é, podemos dizer ainda que todos possuem a obrigação de 
preservar e resguardar o Meio Ambiente, não somente o governo e os atores políticos, mas toda a sociedade.

O autor espanhol Luño (2013) entende que a solidariedade é um valor que nos orienta como uma bússola no que concerne a igualdade, também essencial para os constitucionalismos. Sua dimensão nas demandas ambientais excede as fronteiras nacionais gerando um direito à coletividade que também pressupõe uma distribuição igualitária dos direitos a saúde, vida e no que concerne o direito à moradia digna e legítima.

Contudo, entender a categoria desenvolvimento sustentável é questão de ampla complexidade. Para Bosselmann "[...] a necessidade de conciliar desenvolvimento econômico com a proteção ao meio ambiente está de forma adequada expressa no conceito de desenvolvimento sustentável" (BOSSELMANN, 2015). o que se busca não é reduzir de forma total o desenvolvimento econômico em benefício da sustentabilidade, pois em efeito bumerangue estaríamos trazendo uma massa de desempregados e incentivando a pobreza e a miséria. Sempre há um risco. Busca-se um equilíbrio entre o econômico e o sustentável, ainda que se pareça utópico, é uma chance.

Beck pontua que mesmo que pareça impossível solucionar algum problema, devemos tomar alguma atitude frente a ele. Não basta manter uma distância crítica desta crise civilizatória geradora de riscos com escárnios, cinismos e indiferenças só porque parece que o fim é inevitável. Ainda que de forma minoritária, devemos fomentar alguma ideia, estabelecer parâmetros, propor soluções. Ainda que aparentem serem utópicas, a terra é o nosso lar (BECK, 2011).

\subsection{Sustentabilidade nas cidades e os desafios para a efetivação dos direitos fundamentais}

Para a compreensão de uma possível cidade sustentável, 
torna-se fundamental analisar primeiramente o Estatuto da $\mathrm{Ci}$ dade, que se trata da Lei n. 10.257, de 10 de julho de 2001 (BRASIL, 2001, grifo nosso), que regulamenta os arts. 182 e 183 da CRFB irá dispor o seguinte:

Art. $2^{\circ}$ A política urbana tem por objetivo ordenar o pleno desenvolvimento das funções sociais da cidade e da propriedade urbana, mediante as seguintes diretrizes gerais:

I - garantia do direito a cidades sustentáveis, entendido como o direito à terra urbana, à moradia, ao saneamento ambiental, à infraestrutura urbana, ao transporte e aos serviços públicos, ao trabalho e ao lazer, para as presentes e futuras gerações.

Sob esse prisma, percebe-se que sustentabilidade apesar de se tratar de uma questão global que rompe fronteiras e ultrapassa os horizontes, levando alguns a pensar até mesmo em uma possível sustentabilidade transnacional, também se trata de uma questão local que merece ênfase e efetivação.

Romero (2007, p.51) entende cidade sustentável como sendo:

[...] o assentamento humano constituído por uma sociedade com consciência de seu papel de agente transformador dos espaços e cuja relação não se dá pela razão natureza-objeto e sim por uma ação sinérgica entre prudência ecológica, eficiência energética e equidade socioespacial.

Nesse interim, o desenvolvimento sustentável deve ser pensado principalmente nas cidades que regem as economias dos estados que se espalham por todo o país. Sob esta afirmativa, Leite \& Awad (2012, p. 08) enfatizam que "O desenvolvimento sustentável é o maior desafio do século 21. A pauta da cidade é, no planeta urbano, de maior importância para todos os países". Isso se fundamenta quando percebemos que a) dois terços do consumo mundial de energia advêm das cidades, b) $75 \%$ dos resíduos são gerados nas cidades e c) vive-se processo dramático de esgotamento dos 
recursos hídricos e de consumo exagerado de água potável. Tudo começa na cidade, sendo assim, uma conscientização local, fomento de atitudes sustentáveis e políticas públicas que efetivem o princípio da sustentabilidade na cidade é de importância crucial para o desenvolvimento do país, e em consequência, de todo o mundo.

\section{CONCLUSÃO}

Conclui-se então a presente pesquisa destacando o aproveitamento em relação ao tema abordado e, no decorrer, enfatiza-se as diversas publicações e participações em grupos de estudo, seminários e congressos referentes a temática Sustentabilidade, Direito Urbano e Políticas Públicas.

No que concerne o objetivo geral, percebeu-se que a periferia se encontra marginalizada e rejeitada no contexto urbano. A inserção de Políticas Públicas é restringida por não haver interesse estatal e em decorrência disso, até mesmo o direito a moradia torna-se inviabilizado, dificultando a implementação da Regularização Fundiária. Contudo, nota-se que o conceito de Sustentabilidade abrange toda a coletividade, para cidade sustentável efetiva, os direitos fundamentais de todos os cidadãos precisam ser reconhecidos, e a eles cabe o papel de exercer sua cidadania e participar ativamente no processo democrático de conquista dos seus direitos.

Em relação aos objetivos específicos, a Regularização Fundiária foi destacada como instrumento efetivador do direito à moradia. Verificou-se seus desdobramentos, bem como suas modalidades e as formas de utilização desse importante mecanismo que converte os títulos de posse em propriedade, principalmente daqueles que carecem deste auxílio estatal para tanto. Nesse contexto, percebeu-se a desigualdade existente no cenário urbano e ainda foi destacado a questão da Sustentabilidade como um paradigma a ser efetivado, inclusive nas 
cidades, por meio da concepção de que o mundo não é um baú de recursos infindável, mas a terra merece ser cuidada, pois se trata de nosso único lar.

Em suma, a presente pesquisa foi de grande utilidade para o aperfeiçoamento dos conhecimentos em relação a matéria, bem como para fomentar a discussão em relação a temática, que ainda é desconhecida por grande maioria, mas já possui programas a exemplo do "Programa Lar Legal", que fornece essas oportunidades para toda a comunidade. Sendo assim, percebeu-se a finalidade da Governança urbana, com a parceria entre entes estatais e privados, a consolidação de Políticas Públicas e a efetivação de Direitos Fundamentais salta do campo da teoria e ganha vida na prática. Isso é fundamental.

\section{REFERÊNCIAS}

ARAÚJO. Mayara Mychella Sena. Habitação e governança urbana em feira de santana-bahia: análises sobre o programa Minha Casa Minha Vida. Disponível em: $<$ http:// periodicos.uesb.br/index.php/ascmpa/article/viewFile/3718/3403>. Acesso em: 30 maio 2017.

BOBBIO, Norberto. A era dos direitos. Tradução Carlos Nelson Coutinho. Rio Janeiro: Elsevier, 2004.

BOFF, Leonardo. Sustentabilidade: o que é: o que não é. Rio de Janeiro: Vozes, 2013

BOSSELMANN, Klaus. O princípio da sustentabilidade: transformando direito e governança. Tradução de Phillip Gil França. São Paulo: Revista dos Tribunais, 2015.

BRASIL. Lei n. 10.257, de 10 de julho de 2001. Estatuto da cidade. Disponível em: $<$ http://www.planalto.gov.br/ccivil_03/leis/LEIS_2001/L10257.htm>. Acesso em: 30 maio 2017.

BRASIL. Supremo Tribunal Federal. Acórdão. Brasília, DF. 30 de outubro de 1995. Relator Celso de Mello. Mandato de Segurança n. 221645, Tribunal de Justiça de São Paulo. Publicação Diário de Justiça17-11-1995 PP-3P206 EMENT Vol-01809-05 PP101155. Disponível em: <http://stf.jusbrasil.com.br/jurisprudencia/745049/mandadode-seguranca-ms-22164-sp>. Acesso em: 30 maio 2017.

CAPRA, Fritjof. As conexões ocultas: ciência para uma vida sustentável. Tradução de Marcelo Brandão Cipolla. São Paulo: Cultrix, 2005.

CAPRA, Fritjof. Teia da vida: uma nova compreensão científica sobre os sistemas vivos. Tradução de Tradução Newton Roberval Eichemberg. São Paulo: Cultrix, 2006.

CYMBALISTA, Renato. Política urbana e regulação urbanística no Brasil. In: BUCCI, 
Maria Paula Dallari. Políticas públicas: reflexões sobre o conceito jurídico. São Paulo: Saraiva, 2008.

FREY. Klaus. Governança urbana e redes sociais: o potencial das novas tecnologias da informação e comunicação. Disponível em: <http://www.anpad.org.br/diversos/trabalhos/EnANPAD/enanpad_2003/GPG/2003_GPG2072.pdf>. Acesso em: 30 maio 2017.

GUDYNAS, Eduardo. Cidadania ambiental e metas cidadanias ecológicas. Revista de Desenvolvimento e Meio Ambiente, Curitiba, n. 19, p. 62, jan./jun. 2009. Disponível em: <http://ojs.c3sl.ufpr.br/ojs/index.php/made/article/view/13954>. Acesso em: 30 maio 2017.

HIRST, P. Democracy and governance. In: Jon Pierre (org.): Debating governance: authority, steering and democracy. Oxford University Press: New York, 2000.

LEITE, Carlos; AWAD, Juliana diCesare Marques. Cidades sustentáveis, cidades inteligentes: desenvolvimento sustentável num planeta urbano. Porto Alegre: Bookman, 2012.

McCARNEY, P., M. HALFANI \& A. RODRIGUEZ (1995): Towards an understanding of governance: the emergence of an idea and it's implications for urban research in developing countries. In: Perspectives on the City: Volume 4 of Urban Research in the Developing World (Centre for Urban Community Studies, University of Toronto). Edited by R. Stren\& J. Kjellberg Bell, Toronto.

NALINI, José Renato et al. Regularização fundiária. Coordenadores: José Renato Nalini e Wilson Levy. 2. ed. rev., atual. e ampl. Rio de Janeiro: Forense, 2014.

NALINI, José Renato. Direitos que a cidade esqueceu. São Paulo: Revista dos Tribunais, 2011.

NEVES. Estela Maria Souza Costa. Política e gestão ambiental no contexto municipal. Disponível em: <http://www.kas.de/wf/doc/14818-1442-5-30.pdf>. Acesso em: 30 maio 2017.

PASOLD, Cesar Luiz. Metodologia da pesquisa jurídica: teoria e prática. 13. ed. rev. atual amp. Florianópolis: Conceito Editorial, 2015.

PÉREZ LUÑO, Antonio-Enrique. Las generaciónes de los Derechos Humanos. Revista Direitos Emergentes na Sociedade Global. v. 2, n.1, p.163-169, 2013. Disponível em: $<$ http://periodicos.ufsm.br/REDESG/article/view/10183\#.V47An4-cHIU>. Acesso em: 30 maio 2017.

RHODES, Rod. The new governance: governing without government, Political studies, XLIV. 1996.

ROMERO, Marta A. B. Frentes do urbano para a construção de indicadores de sustentabilidade intra urbana. In: Paranoá: cadernos de arquitetura e urbanismo da FAU-UnB. Ano 6, n. 4 (novembro/2007). - Brasília: FAU UnB, 2007a.

STEPHENS, G. R., AND N. WIKSTROM.Metropolitan Government and Governance.Theoretical Perspectives, Empirical Analysis, and the Future .Oxford University Press, New York. 2000.

TRINDADE, André Karam; ESPÍNDOLA, Ângela Araújo da Silveira; BOFF, Salete Oro. Direito, democracia e sustentabilidade: anuário do Programa de Pós-Gradua- 
ção Stricto Sensu em Direito da Faculdade Meridional. Passo Fundo, (RS): Editora IMED, 2015.

ZANTA. Viviana Maria. Gestão de resíduos sólidos nas capitais brasileiras: um olhar sob a ótica da governança e sustentabilidade. Disponível em: <http://www.kas.de/wf/ doc/14818-1442-5-30.pdf>. Acesso em: 30 maio 2017.

Artigo recebido em: 03/06/2017

Artigo aprovado em: 06/10/2017 